\title{
INVESTIGATIONS ON TOXIC, ANTIFEEDANT AND REPELLENT PROPERTIES OF THE DEFENSIVE SECRETION OF CORIDIUS JANUS (HEMIPTERA;PENTATOMIDAE) AND A SYNTHETIC MIXTURE OF ITS MAJOR VOLATILE CONSTITUENTS
}

\author{
ASOKA PATHIRATNE*, NEELAKANTHI E. GUNAWARDENA** AND \\ SHIROMA K.J. LIYANAGE* \\ *Department of Zoology/ ${ }^{* *}$ Department of Chemistry, \\ University of Kelaniya, Kelaniya, Sri Lanka.
}

(Date of receipt : 05 March 1991)

(Date of acceptance : 30 May 1991)

\begin{abstract}
Effectiveness of defensive secretion of Coridius janus and a synthetic mixture of its two major volatiles, t-2-hexenal and n-tridecane $(60: 40 \mathrm{w} / \mathrm{w})$ was assayed as topical applicants, fumigants, antifeedants, irritants and repellents against seven insect pests, Periplaneta americana, Sitophilus oryzae, Tribolium castaneum, Musca domestica, Oecophylla smaragdina, Eurema hecabe and Dysdercus cingulatus. The effectiveness of the test materials was found to be dependent on their mode of application and the species of test insect. There was a parallelism in the activities of the natural defensive secretion and, the synthetic mixture. Generally, both test materials performed poorly when tested as topical applicants and fumigants, although, the natural defensive secretion showed some effect as a topical applicant against adults of $S$. oryzae, and $M$. domestica $\left(\mathrm{LD}_{\mathrm{s0}}<\mu \mathrm{\mu g}\right)$. Both test materials were remarkably effective antifeedants against $S$. oryzae and $E$. hecabe. These also proved equipotent as irritants against $P$. americana and as repellents to $D$. cingulatus and $O$. smaragdina. It is suggested that the synthetic chemical mixture may be used for effective insect pest control.
\end{abstract}

\section{Introduction}

Natural pesticides of plant origin such as pyrethrins and cinerins have long been used in the control of various insect pests. In the recent past, secretions of insect origin have also received attention. Consequently, insect pheromones, insect juvenile hormone and its analogues have been recognized and are presently being used as a part of the integrated pest management strategies with varying degrees of success. In contrast, a large number of insect defensive secretions have been characterised $1,2,4,17$ although no effort has been made in using these as possible agents for pest control strategies. Nevertheless several biological aspects of insect defensive secretions such as toxic properties, ${ }^{3}$ alarm pheromone activity and repellent properties have been recognized in insect defensive secretions.

Coridius janus Fabricius (Hemiptera:Pentatomidae) inhabits the dry zone of Sri Lanka. It feeds mainly on sweet pumpkin (Cucurbitaceae) and does not cause a great threat to the host plant unless pest population rises very high. This insect ejects a defensive secretion which has a pungent smell. A previous study ${ }^{11}$ on the defensive secretion of $C$. janus has shown that it possesses fairly high fumigant properties towards three test insects viz. Anoplolepis longipes (Formicidae), Culex quinquefasciatus (Culicidae) and Sitotroga cerealella (Gelechiidae). This study also revealed that the two major volatiles of this secretion, $t$-2-hexenal and $n$-tridecane which comprise $90 \%$ of the total volatiles of the secretion are mainly responsible for 
the above fumigant property. Further, a synthetic combination of t-2-hexenal : $\mathrm{n}$-tridecane $(60: 40, \mathrm{w} / \mathrm{w})$ was shown to possess the highest fumigant activity compared to all other possible combinations of the above chemicals.

The present study was undertaken to compare the effectiveness of the natural defensive secretion with that of a synthetic mixture of its major volatiles $\mathrm{t}$-2-hexenal/n-tridecane $(60: 40, \mathrm{w} / \mathrm{w})$, as topical applicants, fumigants, antifeedants, irritants and repellents against a variety of insect orders. This information could be of value for insect pest control strategies using natural products.

\section{Experimental}

\subsection{Rearing of Coridius janus and Species of Test Insects}

Live individuals of $C$. janus were collected from their natural habitats, the sweet pumpkin fields at Aulegama, Kurunegala District. In the laboratory, they were caged in small groups and maintained for weeks on fresh leaves of sweet pumpkin.

In this study, seven species of insects belonging to six different orders were used as test insects. These insects were collected from their natural habitats and allowed to multiply under laboratory conditions in separate culture containers. The species of test insects used are listed in Table 1, together with the food on which they were maintained in the laboratory. Rearing of four species of test insects, $P$. americana, $M$. domestica, $S$ : oryzae, $T$. castaneum in the laboratory were carried out following the methods described by Peterson. ${ }^{13}$ Rearing of O.smaragdina in the laboratory was unsuccessful. The insects (soldiers) collected from their natural habitats were, therefore used for the experiments. They could be maintained on glucose and water for 4-6 days until they were used in the experiments.

The adults of $E$. hecabe were reared on $4 \%$ sucrose solution or nectar of flowers in rectangular glass tanks [1' $\times 2$ ' $\times 2$ ', 5 male: 5 female/tank] tightly covered with a piece of mosquito net for ventilation. Two polythene bag pots containing young plants of Kathurumurunga (Sesbania grandiflora) were placed in each tank so that the adult female butterflies could lay eggs on these leaves. When the eggs were hatched, the caterpillars were transferred into plastic bottles $(4 \mathrm{~L})$ covered with pieces of mosquito net for ventilation. The caterpillars were reared on leaves of Kathurumurunga. The 2nd instar larvae (1-1.5 cm in length) were used in the experiments.

Nymphs and adults of $D$. cingulatus were reared on fruits or leaves of Okra in insect cages fitted with metallic mesh. Only the adult stage was used in the experiments.

All insect rearing cages were cleaned regularly. The moisture content of the rearing cages was maintained by keeping moist cotton balls in small containers in the cages with the insects. The temperature of the laboratory during the experimental period was $28 \pm 2^{\circ} \mathrm{C}$. 
Table 1: Species of test insects used in the experiments

\begin{tabular}{|c|c|c|}
\hline Order & Species of test insects & Offered food source \\
\hline Dictyoptera & Periplaneta americana (cockroach) & $\begin{array}{l}\text { Banana, Potato, Bread, } \\
\text { Water }\end{array}$ \\
\hline Coleoptera & Sitophilus oryzae (rice weevil) & Rice \\
\hline Coleoptera & Tribolium castaneum (flour beetle) & $\begin{array}{l}\text { White flour, Gingelly } \\
\text { seeds }\end{array}$ \\
\hline Diptera & Musca domestica (house fly) & $\begin{array}{l}\text { Diluted milk, Sugar, } \\
\text { Dried fish }\end{array}$ \\
\hline Hymenoptera & $\begin{array}{l}\text { Oecophylla smaragdina } \\
\text { (red ant-soldiers) }\end{array}$ & Glucose, Water \\
\hline Lepidoptera & $\begin{array}{l}\text { Eurema hecabe (grass yellow) } \\
\text { adult } \\
\text { caterpillar }\end{array}$ & $\begin{array}{l}4 \% \text { Sucrose, Flowers } \\
\text { Kathurumurunga leaves }\end{array}$ \\
\hline Hemiptera & $\begin{array}{l}\text { Dysdencus cingulatus } \\
\text { (cotton stainer) }\end{array}$ & Okra fruit and leaves \\
\hline
\end{tabular}

\subsection{Chemicals}

Trans-2-hexenal and n-tridecane were purchased from Aldrich Chemical Co. Ltd., UK and found to be $99.9 \%$ pure by GLC. Liquid paraffin and acetone were purchased from $\mathrm{BDH}, \mathrm{UK}$.

\subsection{Preparation of Test Materials for Bioassay}

Natural defensive secretion of $C$. janus was obtained by placing insects in preweighed glass vials and pinching their legs with fine forceps until the defensive secretion was ejected. The insects were removed from the vials immediately after the ejection. The vials were weighed and frozen until they were used in the experiments.

Synthetic mixture, $t-2$-hexenal/n-tridecane $(60: 40, w / w)$ was prepared by mixing thoroughly the neat liquids of 2 -hexenal and n-tricecane in the ratio of $60: 40(\mathrm{w} / \mathrm{w})$ until a single phase was obtained and weighing out from this mixture appropriate amounts into small glass vials.

\subsection{Studies on Activity of the Defensive Secretion}

\subsubsection{Topical application}

Preliminary studies showed that the fresh defensive secretion of $C$. janus was lethal to the species of insects tested. Immediate death of some species of insects was observed after applying very small amounts $(0.2-0.4 \mu 1)$ of the defensive secretion onto the thorax of the insects using a micro-applicator. The natural secretion was therefore diluted with a suitable non toxic solvent. For each test species the suitable non toxic solvent was selected by applying a series of doses (in the range of $0.2-1.2 \mu 1$ ) of the 
solvents, and observing the mortality after 24 hours. Acetone was found to be the most suitable non toxic solvent for all the test species except $M$. domestica, for which paraffin oil was found to be suitable.

For studies of activity, the natural defensive secretion was diluted with the selected suitable solvent and various doses (as drops) were applied onto the thorax of each test insect. Insects treated with only the solvent served as controls. After the treatment, the insects were placed separately in recovery cages. Glass vials, tubes or flasks of various sizes (depending on the size of the species of test insect) covered with pieces of mosquito net or perforated plastic caps were used as recovery cages. Mortality was recorded after 24 hours. Each dose was tested three times with different batches of insects and minimum number of 10 insects were used for each dose. $\mathrm{LD}_{50}$ values were calculated by Probit analysis of data as described by Busvine. ${ }^{6}$

The activity of the synthetic mixture was also tested as described above.

\subsubsection{Fumigant property}

C. janus in a preweighed small vial was made to eject its defensive secretion. Immediately after the secretion was ejected, $C$. janus was removed and the vial was closed and weighed. This vial was introduced into an airtight, large, glass container (10L) where test insects $(20-30)$ had been placed about $1 / 2 \mathrm{hr}$ prior to the experiments. Small vials containing the defensive secretion or the synthetic mixture were then opened and the volatiles allowed to diffuse into the large glass container. Mortalities were recorded after 24 hours. Small vials were weighed again in order to make sure that all materials had volatilized into the glass container. Distilled water was used in the control experiments. A series of concentrations were tested, and triplicates were run for each test. The $\mathrm{LC}_{50}$ values were calculated by Probit analysis of data. ${ }^{6}$

\subsubsection{Antifeedant activity}

Two species of test insects $S$. oryzae, and $E$. hecabe were used in this study.

\subsection{3a Antifeedant studies using S. oryzae}

The test insects were starved for 24 hours prior to the experiments. Known quantities of rice grains ( $500 \mathrm{mg} / \mathrm{test})$ were coated evenly $(0.2 \mu \mathrm{l} /$ grain) with acetone, a series of concentrations of the natural secretions, the synthetic mixture diluted with acetone respectively. The treated rice grains were placed separately in labelled $12.5 \mathrm{ml}$ glass vials $(500 \mathrm{mg}$ rice/vial). Twenty starved insects were added to each vial and the vials were closed with perforated plastic caps for ventilation. A group of insects in a vial with untreated rice grains was used as control. Mortality counts were taken daily and the weight of the remaining rice grains were 'recorded after 4 days. Triplicates were run for each test. The reduction in weight of rice compared to that of untreated rice indicated the antifeedant activity. 


\subsection{3b Antifeedant studies using $E$. hecabe}

The 2nd instar larvae of $E$. hecabe (1.0-1.2 cm in length) were used in this study. The larvae were starved for 2 hours prior to the experiments. Fresh Kathurumurunga leaves containing 10 leaflets (length range $3.8-4 \mathrm{~cm}$ ) were coated evenly with acetone/natural secretion/synthetic mixture diluted with acetone. Each leaf was placed in a small vial containing small amount of water to maintain turgidity. This leaf was put in a plastic bottle (2L) and a caterpillar was placed on the treated leaf. The plastic bottle was covered with a perforated cap for ventilation. Ten caterpillars were tested for each treatment. The caterpillars in the bottles with untreated leaves served as controls. After 12 and 24 hour periods, the leaves were examined and the number of leaflets eaten by the caterpillars counted. For the partially eaten leaflets, the amount eaten was recorded by the use of squared paper. The reduction in the amount of treated leaves compared to that of the untreated leaves indicated the antifeedant activity.

\subsubsection{Imitant/repellent activity}

\subsection{4a Preliminary tests for deterrent activity}

These tests were carried out following the method described by Eisner et al..$^{9}$ The test consisted of observing the response of a variety of insects to the vapours emanating from the tip of a capillary tube filled with the defensive secretion, presented to the insects manually at near contact range. A glass capillary tube filled with distilled water was presented to the insect first from one side of the body $(5 \mathrm{sec}$.) and then the other side $(5 \mathrm{sec}$.). If the response to the control was negative (no movement towards or away from the capillary tube), a capillary tube filled with the natural secretion or synthetic mixture was presented ( $5 \mathrm{sec}$. on each side of body). The response was scored as positive if the insect turned away from the chemical under study both times.

\subsection{4b Topical test for imitant activity}

In nymphs of the cockroach $P$. americana, application (or near contact presentation) of a droplet of irritant to one side of abdominal tergite 4 or 5 evoked an accurately directed scratch reflex from the ipsilateral leg. The behaviour provides a basis for assay of topical irritancy of chemicals or their vapours. ${ }^{12}$. This technique was used in the present study to test the irritancy of the natural secretion and the synthetic mixture. Late-instar decapitated nymphs were used. Stimulation was affected by contact presentation (1\% solutions in paraffin oil with $0.2 \mu 1$ droplets applied by microsyringe) or near contact presentation (glass capillary tube with pure sample held at less than $1 \mathrm{~mm}$ from the tergite surface). Irritancy of sample was scored as percent individuals that responded within 20 seconds of stimulation.

\subsection{4c Olfactometer bioassay for repellent activity:}

Two species of test insects $O$. smaragdina and $D$. cingulatus were used in this study. A simple $Y$ shaped insect olfactometer described by Gunawardena et al. ${ }^{10}$ was used with slight modifications (Figure 1). A capillary tube with the chemical under investigation 
(natural secretion or synthetic mixture) was kept in arm A. A capillary tube filled with distilled water was kept in arm B. A group of 20 test insects confined in the tube C was introduced to the main tube from the opposite end. These insects were made to move slowly towards the two arms of the olfactometer by gently warming the tube $\mathrm{C}$ $\left(35^{\circ} \mathrm{C}-45^{\circ} \mathrm{C}\right)$. Proceeding towards the two arms, (A and $\left.\mathrm{B}\right)$, insects encountered the air currents carrying the test compounds and made their selection of the arms ( $\mathrm{A}$ or B). The number of insects in a particular arm was noted after $5 \mathrm{~min}$. Batches of 20 insects were used at a time and each chemical was tested with four batches of insects. The test insects were not used repeatedly and parts of the apparatus likely to be contaminated were cleaned by washing and blowing air for $15 \mathrm{~min}$ before testing with a new batch of insects. The temperature of the laboratory during the period of this experiment was $28 \pm 1^{\circ} \mathrm{C}$ and relative humidity $80 \pm 4 \%$.

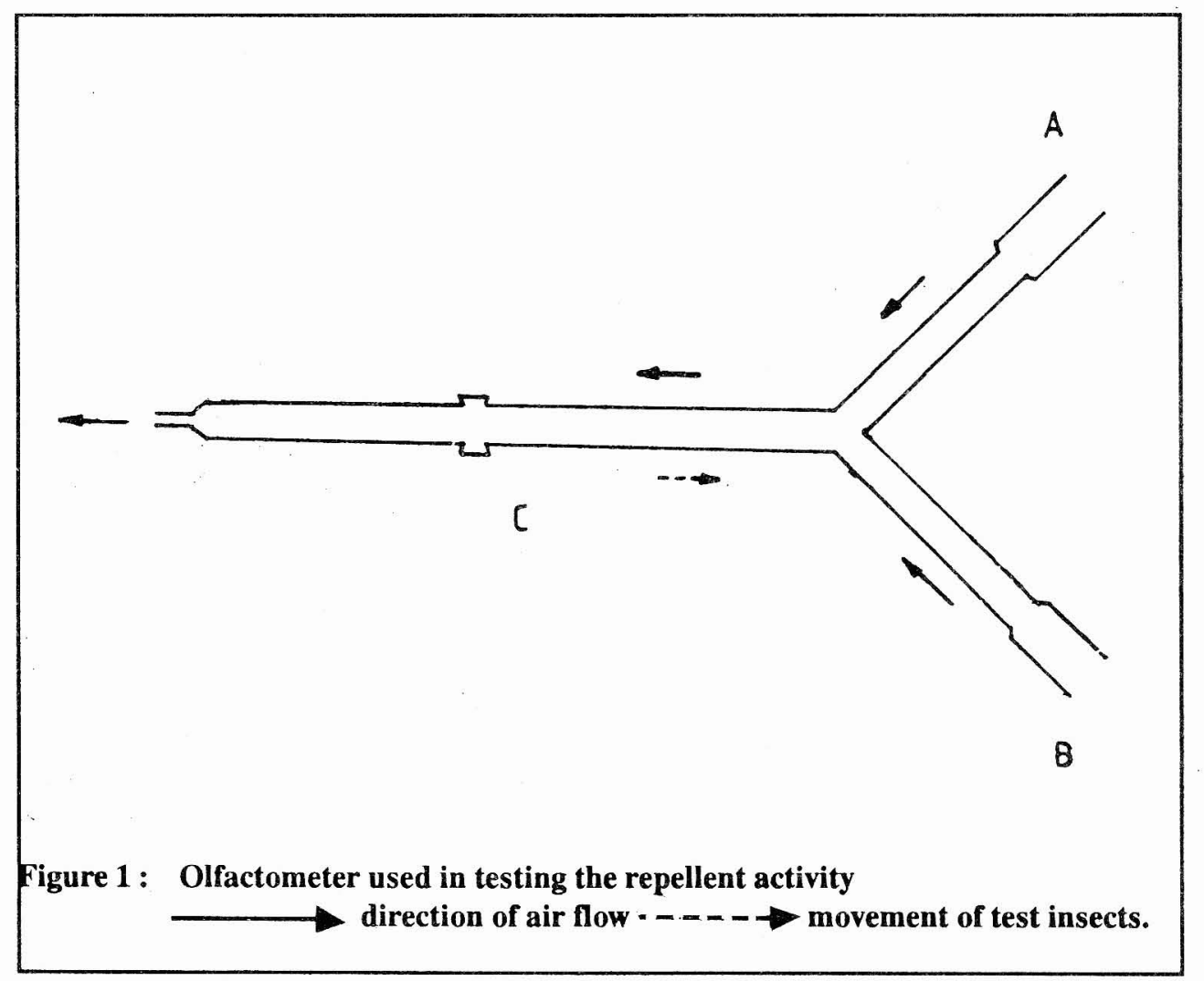

\section{Results}

\subsection{The Defensive Gland Structure}

The defensive gland of $C$. janus possesses a large bilobed, heartshaped median reservoir. The reservoir is reddish orange to dark red in colour. The gland is situated ventrally between the metathoracic legs and the reservoir extends back into the 2nd abdominal segment when distended with secretion. The two openings from the reservoir emerge on the ventral side near the anterior edge of the metasternum lateral 
to the coxal cavity. The wall of the reservoir has many fine cross striations and irregular foldings which permit great distension. The secretion is yellow in colour. The volume of the secretion stored in the gland varies with the sex, the size of the individual and whether or not it has discharged recently. Not all the secretion is necessarily discharged on any one occasion. From a single individual $6-8 \mathrm{mg}$ of fluid have been collected on some occasions.

\subsection{Properties of Defensive Secretion and the Synthetic Mixture}

\subsubsection{As a topical applicant}

24 hour $L_{50}$ values for the test insects obtained by the method of topical application are listed in Table 2. Rice weevils ( $S_{\text {. oryzae }}$ ) and house flies (M. domestica) were the most susceptible test insects ( $\mathrm{LD}_{50}<1 \mu \mathrm{g}$ ) to the defensive secretion. Adult cockroaches were not affected even at dosages upto $1 \mathrm{mg}$. Other test insects were moderately susceptible $\left(1 \mu \mathrm{g}<\mathrm{LD}_{50}<0.125 \mathrm{mg}\right)$. The synthetic mixture was found to be less potent than the natural secretion of $C$. janus. All the test insects except cockroaches were moderately susceptible to the synthetic mixture. However the LD50 values were somewhat higher than those of the natural secretion.

Table 2: 24 hour $L D_{50}$ values of matural secretion and synthetic mixture (Topical application)

\begin{tabular}{lcc}
\hline Test Insect $^{\mathrm{a}}$ & \multicolumn{2}{c}{$\mathrm{LD}_{50}(\mu \mathrm{g})^{\mathrm{b}}$} \\
\cline { 2 - 3 } & Natural secretion & Synthetic mixture \\
\hline Periplaneta americana & $>1000$ & $>1000$ \\
Musca domestica & $0.8(0.4-1.3)$ & $5.6(3.4-7.9)$ \\
Tribolium castaneum & $21.3(18.1-24.6)$ & $391(319-463)$ \\
Sitophilus onzae & $0.4(0.2-0.7)$ & $298(257-339)$ \\
Eurema hecabe & $121(96-145)$ & $318(296-329)$ \\
Oecophylla smaragdina & $48.1(39.2-58.9)$ & $117(82-152)$ \\
Dysdercus cingulatus & $5.2(2.8-9.2)$ & $17.5(6.7-28.4)$ \\
\hline
\end{tabular}

alarvae of $E$. hecabe and adults of other insects were used as test insects.

${ }^{b}$ Natural secretion $=$ defensive secretion of Coridius janus, Synthetic mixture $=\mathrm{t}$-2-hexenal $: \mathrm{n}$-tridecane $(60: 40 \mathrm{w} / \mathrm{w})$, The numbers in parantheses indicate the $95 \%$ confidence limits.

\subsubsection{As a fumigant}

24 hour LC $_{50}$ values for the storage pests obtained by fumigation method are listed in Table 3. Defensive secretion of $C$. janus and the synthetic mixture showed only a little promise as a fumigant against $S$. oryzae. 
Table 3: 24 hour $\mathrm{LC}_{50}$ values of natural secretion and synthetic mixture (Fumigation)

\begin{tabular}{lcc}
\hline Test insect $^{\mathrm{a}}$ & \multicolumn{2}{c}{$\mathrm{LC}_{50}(\mathrm{ppm})^{\mathrm{b}}$} \\
\cline { 2 - 3 } & Natural secretion & Synthetic mixture \\
\hline Tribolium castaneum & $12.10(9.81-14.49)$ & $18.10(14.26-21.95)$ \\
Sitophilus oryzae & $5.72(3.01-8.44)$ & $8.73(6.80-10.86)$ \\
\hline a adults of test insects were used. & \\
b Natural secretion $=$ defensive secretion of Coridius janus, Synthetic mixture $=\mathrm{t}-2$-hexenal : $\mathrm{n}$-tridecane \\
$(60: 40 \mathrm{w} / \mathrm{w})$, Number in parantheses indicate the $95 \%$ confidence limits.
\end{tabular}

\subsubsection{As an antifeedant}

The natural secretion of $C$. janus and the synthetic mixture were shown to be potent antifeedants to S. oryzae (Table 4) and E. hecabe (Table 5).

Table 4 : Response of Sitophilus oryzae to the offered food sources treated with natural secretion or synthetic mixture

Food source

Food consumption

$\mu \mathrm{g} / 20$ insects/4 days

Rice (control)

$86.37 \pm 5.67^{b}$

Rice + acetone

$88.07 \pm 7.19^{b}$

Rice + Natural secretion

$0.04 \mu \mathrm{g}$

$26.40 \pm 4.31^{\mathrm{c}}$

$\begin{array}{ll} & 0.40 \mu \mathrm{g} \\ & 4.00 \mu \mathrm{g} \\ \text { Rice + Synthetic mixture } & 0.04 \mu \mathrm{g} \\ & 0.40 \mu \mathrm{g} \\ 4.00 \mu \mathrm{g}\end{array}$

$14.75 \pm 3.65^{\mathrm{d}}$

$6.18 \pm 2.90^{\mathrm{e}}$

$16.11 \pm 2.16^{d}$

$15.33 \pm 2.05^{\mathrm{d}}$

$10.67 \pm 2.65^{\mathrm{d}, \mathrm{e}}$

${ }^{a_{N a t u r a l}}$ secretion $=$ Defensive secretion of Coridius janus, Synthetic mixture $=\mathrm{t}$-2-hexenal $: \mathrm{n}$-tridecane $(60: 40 \mathrm{w} / \mathrm{w})$, Results are presented as mean $\pm \mathrm{SD}, \mathrm{n}=4$.

b-d Means not followed by the same letter are significantly different $p<0.05$ (ANOVA, Duncan's Multiple Range test). 
Table 5: Response of Eurema hecabe larvae to the offered food source (Kathurumurunga leaves) (Sesbania grandiflora) treated with natural secretion or synthetic mixture

\begin{tabular}{lcc}
\hline Food source & \multicolumn{2}{c}{ Number of leaflets consumed/insect } \\
\cline { 2 - 3 } & \multicolumn{1}{c}{$12 \mathrm{hr}$} & $24 \mathrm{hr}$ \\
\hline Untreated leaves (control) & $3.98 \pm 0.73^{\mathrm{c}}(3-5.25)$ & $6.23 \pm 1.33^{\mathrm{c}}(4-8)$ \\
Leaves + acetone & $4.58 \pm 0.74^{\mathrm{c}}(4-5.75)$ & $5.51 \pm 2.22^{\mathrm{c}}(4.25-8)$ \\
Leaves + natural secretion & & \\
$\begin{array}{c}\text { 1\% solution } \\
10 \% \text { solution }\end{array}$ & $0.71 \pm 0.22^{\mathrm{d}}(0.5-1.0)$ & $1.05 \pm 0.33^{\mathrm{d}}(0.5-1.5)$ \\
Leaves + synthetic mixture & $0.14 \pm 0.12^{\mathrm{e}}(0-0.25)$ & $0.28 \pm 0.17^{\mathrm{e}}(0.25-0.5)$ \\
$1 \%$ solution & $0.88 \pm 0.32^{\mathrm{d}}(0.5-1.5)$ & $1.23 \pm 0.25^{\mathrm{d}}(1.0-1.5)$ \\
$10 \%$ solution & $0.09 \pm 0.08^{\mathrm{e}}(0-0.25)$ & $1.18 \pm 0.30^{\mathrm{d}}(1.0-2.0)$ \\
\hline
\end{tabular}

${ }^{a}$ Natural secretion $=$ defensive secretion of Coridius janus, synthetic mixture $=\mathrm{t}$-2-hexenal $: \mathrm{n}$-tridecane $(60: 40 \mathrm{w} / \mathrm{w})$,

${ }^{b}$ Results are presented as mean $\pm S D, n=10$, numbers in parantheses indicate the range of leaflets consumed by caterpillars,

${ }^{c-d}$ Means in one column, not followed by the same letter are significantly different $p<0.05$ (ANOVA,Duncan's Multiple Range test).

The antifeedant activity of the secretion of $C$. janus seems to be dependent on its dosage. The secretion and the synthetic mixture were tested with $S$. oryzae at three dosage levels. At the highest dosage $(4 \mu \mathrm{g})$, only $7 \%$ of the treated rice was eaten. (The weight of untreated rice eaten by the weevils was considered as $100 \%$ ). At a dosage of $0.04 \mu \mathrm{g}, 30 \%$ of the treated rice was consumed. At the intermediate dosage $(0.4 \mu \mathrm{g})$ activity was intermediate showing only $17 \%$ consumption. The mortality of the insects during the experiment was negligible $(0.5 \%)$. However, $10-55 \%$ of the insects which consumed rice treated with natural secretion of $C$. janus or the synthetic mixture were dead after a period of 120 hours.

At the dosages of synthetic mixture tested, $12-19 \%$ of the treated rice was eaten. The antifeedant activity does not seem to depend on dosage; no significant difference in the weights of rice consumed were found among the three dosage levels $(P>0.0 .5)$.

Similar results (Table 5) were obtained for the antifeedant tests with E. hecabe. The defensive secretion and synthetic mixture were potent antifeedants to this species. At the highest dosage of natural secretion of $C$. janus (10\%) only $4.5 \%$ of the treated leaflets was eaten while at $1 \%$ only $17 \%$ was eaten. At the dosage of $1 \%$ and $10 \%$ of the synthetic mixture, $19-20 \%$ of the treated leaflets was eaten. 


\subsubsection{Repellent activity}

Results of the preliminary deterrency test proved that the natural defensive secretion and the synthetic mixture were repellents to all the species tested namely $P$. americana, $M$. domestica, $T$. castaneum, $S$. oryzae, $O$. smaragdina and $D$. cingulatus. The topical irritancy test (Table 6) showed that natural secretion and the synthetic mixture were equally active irritants to cockroaches $(P>0.05)$. However, contact presentation was more active than the presentation of vapour phase of the test materials. The results on the olfactometer bioassay for $O$. smaragdina and D. cingulatus (Table 7) also showed that both the natural secretion and synthetic mixture were equipotent as repellents to both species tested.

Table 6: Topical irritancy of natural secretion and synthetic mixture (Periplaneta americana irritancy test)

Test chemicals ${ }^{\mathrm{a}}$

Time to onset ${ }^{b}$
of response
(sec.)

$\%$ of insects showed the reflex within

$20 \mathrm{sec}$.

Paraffin oil

$\begin{array}{lll}\text { Vapour } & \text { No response } & 0 \% \\ \text { Contact } & \text { No response } & 0 \%\end{array}$

Natural secretion

$\begin{array}{lll}\text { Vapour } & 12.75 \pm 2.88^{\mathrm{c}} & 100 \% \\ \text { Contact } & 3.51 \pm 1.77^{\mathrm{d}} & 100 \%\end{array}$

Synthetic mixture

$\begin{array}{lrr}\text { Vapour } & 16.67 \pm 4.11^{\mathrm{c}} & 90 \% \\ \text { Contact } & 2.86 \pm 0.64^{\mathrm{d}} & 100 \%\end{array}$

\footnotetext{
${ }^{a} 10 \%$ solutions of the chemicals dissolved in paraffin oil were used. Natural secretion $=$ defensive secretion of Coridius janus, Synthetic mixture $=\mathrm{t}$-2-hexenai: $\mathrm{n}$-tridecane $(60: 40 \mathrm{w} / \mathrm{w})$.

${ }^{\mathrm{b}}$ Results are presented as mean $\pm \mathrm{SD}, \mathrm{n}=20$.

$c-d$ Means not followed by the same letter are significantly different $p<0.05$ (ANOVA, Duncan's Multiple Range test).
} 
Table 7: Repellency of natural secretion and synthetic mixture (Olfactometer bloassay)

\begin{tabular}{llccc}
\hline \multirow{2}{*}{ Test insect } & Test chemical $^{\mathrm{a}}$ & \multicolumn{3}{c}{ \% of insects attracted within 5 min. } \\
\cline { 3 - 5 } & & No response & Water & $\begin{array}{l}\text { Test } \\
\text { chemical }\end{array}$ \\
\hline $\begin{array}{l}\text { Oecophylla } \\
\text { smaragdina }\end{array}$ & Natural secretion & 0 & 80 & $20 \mathrm{~b}$ \\
& Synthetic mixture & 10 & 75 & $15^{\mathrm{b}}$ \\
$\begin{array}{l}\text { Dysdercus } \\
\text { cingulatus }\end{array}$ & Natural secretion & 20 & 70 & $10^{\mathrm{b}}$ \\
& Synthetic mixture & 10 & 75 & $15^{\mathrm{b}}$ \\
\hline
\end{tabular}

${ }^{2}$ Natural secretion $=$ defensive secretion of Conidius janus; ; Synthetic mixture $=\mathbf{t}$-2-hexenal $: \mathrm{n}$-tridecane $(60: 40 \mathrm{w} / \mathrm{w}), Y$ shaped olfactometer was used and 20 insects were used for each trial. Number of trials $=4$. ${ }^{b}$ Significantly different at $p<0.025\left(\chi^{2}\right.$ test).

\section{Discussion and Conclusions}

The present study has shown that the response of test insects, belonging to six different orders, to the two test materials under considereation, viz. the defensive secretion of $C$. janus and the synthetic chemicals mixture, depended greatly on the mode of application and the nature of the test insect. As a topical applicant, the defensive secretion was effective $\left(\mathrm{LD}_{50}<1 \mu \mathrm{g}\right)$ against $S$. oryzae and $M$. domestica, whilst other test insects showed poor sensitivity with the hardy $P$. americana adults being unaffected. Considering the chemical and physical differences in the cuticular frame work of test insects belonging to the six different orders, above variations are understandable.

In contrast, antifeedant property was very evident with both test materials under consideration. They showed almost equal effectiveness towards the two insect species tested, viz. S. oryzae (adult) and E. hecabe (caterpillar). The response of these insects to the test materials seemed to be dose dependent. Both insects showed high sensitivity to the test materials at low concentrations and more pronounced effects at higher concentrations.

The high antifeedant property of the defensive secretion of $C$. janus could be attributed to the process of 'self coating', common among insects which produce defensive secretions. Secretory discharges are usually effected by many Hemipterans in a diversity of ways. ${ }^{7,8,16}$ Usually the defensive secretions characteristic of a particular insect species is an optimised chemical formulation suited not only for chemical deterrence of the enemy but self-coating which prevent it being eaten or picked up by predators. Insects which are vulnerable to such predators are known to use this method as a means of self protection. ${ }^{12}$ 
Fumigant properties of the test materials were tested against two species (storage pests) only viz. $S$. oryzae and $T$. castaneum. Results do not appear to be remarkable ( $\mathrm{LC}_{50}<10$ for $S$. oryzae and $\mathrm{LC}_{50}<20$ for $T$. castaneum), but this could be a valuable result in conjunction with the high antifeedant properties of the above two materials towards the storage pest, $S$. oryzae.

Considering the deterrent properties, the defensive secretion as well as the chemical mixture showed equally high effectiveness. Repellent properties also do not differ greatly between the two although the natural defensive secretion was found to be superior. Both test materials were found to be potent irritants to the nymph $P$. americana. It is known that secretions of terrestrial Heteroptera are primarily defensive irritants ${ }^{14,15}$ and hence high irritancy of the defensive secretion is not surprising.

The data showed that the defensive secretion of $C$. janus and its corresponding chemical combination afforded protection against insects. This result is not surprising when the biological aspects of this insect are considered. C. janus is a large, crawling insect which hardly flies. Its vulnerability to predators such as birds and ants found in the sweet pumpkin fields is high, and production of a toxic defensive secretion by $C$. janus is therefore, not surprising.

A marked parallelism in activities of the defensive secretion of $C$. janus and its two major volatile constituents $t-2$-hexenal and $n$-tridecane, $(60: 40 \mathrm{w} / \mathrm{w})$ were shown in this study. This is an important finding for practical application of the findings for control of insect pests. One of the major problems that could arise is the difference in volatilities of the two components of the mixture. Under field conditions there could be a greater loss of more volatile $t$-2-hexenal, resulting in an altered composition. It has been shown previously ${ }^{11}$, that the activity of the above mixture is very dependent on the ratios of the two components, with the $60: 40(\mathrm{w} / \mathrm{w})$ mixture of $t-2$-hexenal; n-tridecane being the most effective. Consequently the use of field sprays for the control of $E$. hecabe may pose problems, although in the case of storage pest, $S$. oryzae, application of the above mixture as an antifeedant will be in a confined area, and hence the chances of it being successful are much higher.

The following conclusions could be drawn from this study. The effectiveness of toxicants, viz. the defensive secretion of $C$. janus and the chemical combination, $t$-2-hexenal and $n$-tridecane $(60: 40 \mathrm{w} / \mathrm{w})$ depends largely on the mode of application and the type of test insect. A parallelism was seen in the activities of defensive secretion of $C$. janus and the combination of its two major volatiles t-2-hexenal and $\mathrm{n}$-tridecane. Among the two test materials however, the natural defensive secretion is slightly more effective than the synthetic mixture as a topical applicant, a fumigant and an antifeedant while both are equally highly active as irritants and repellents.

The most effective modes of activity of test materials were as antifeedants, irritants, and repellents. S. oryzae and $E$, hecabe had high sensitivity to antifeedant activity, whilst nymphs of $P$. americana were markedly susceptible to irritants and $O$. smaragdina and $D$. cingulatus were fairly sensitive when used as repellents. 
In view of the practical implications, the chemical combination t-2-hexenal and n-tridecane could be a satisfactory substitute for the defensive secretion of $C$. janus. Finally, taking into account the volatile nature of $t-2$-hexenal in the above mixture together with the data obtained, two practical applications could be recommended as plausible, viz. the use as an antifeedant against $S$. oryzae and as an irritant against $P$. americana.

\section{Acknowledgements}

Authors thank Natural Resources, Energy and Science Authority of Sri Lanka for funding this research project. Thanks are also due to Dr I. V. S. Fernando for his valuable advice and to Ms. H. W. R. Damayanthi for typing this manuscript.

\section{References}

1. ALDRICH, J. \& YONKE, T. (1975) Natural Products of Abdominal and Metathoracic Scent Glands of Coreoid Bugs. Ann. Entomol. Soc. Amer. 68: 955-960.

2. ALDRICH, J.R. (1988) Chemical Ecology of the Heteroptera, Ann. Rev. Entomol. 33: 211-238.

3. BLUM, M.S. (1964) Insect Defensive Secretions, 2-hexenal in Palmatosilpha coriacea and its Repellent Values Under Natural Conditions. Ann. Entomol. Soc. Am. 57(5): 600-602.

4. BLUM, M.S. (1981) Chemical Defense of Arthropods, 562, Academic Press, New York.

5. BLUM, M.S. (1985) Alarm pheromones, In Comprehensive Insect Physiology, Biochemistry and Pharmacology, 9: 193-224, Oxford, Pergamon.

6. BUSVINE, J.R. (1957) A Critical Reveiw of the Techniques for Testing Insecticides, 167-185, The Eastern Press Ltd., London.

7. CORNER, J. CAMAZINE, S., ANESHANSLEY, D. \& EISNER, T. (1985) Mammalian Breath; Trigger of Defensive Chemical Response in a Tenebrionid Beetle (Bolitotherus comutus). Behav. Ecol. Sociobiol. 16: 115-118.

8. EISNER, T., ANESHASTEY, D., EISNER, M., TUTOWSKE, R., CHENG, B. \& MEINWALD, J. (1974) Chemical Defense and Sound Production in Australian Tenebrionid Beetle. Psyche. 81: 189-208.

9. EISNER, T., DERUP, M., JACOPS, R. \& MEINWALD, J. (1986) Necrodols, Anti-insectan Terpenes from Defensive Secretion of Carrion Beetle (Necrodes surinamensis) J. Chem. Ecol. 12(6): 1410-1415. 
10. GUNAWARDENA, N.E., ATYGALLE, A.B. \& HERATH, H.M.W.K.B. (1989) The Sex Pheromone of the Brinjal Pest, Leucinodes orbonalis Guenee (lepidoptera): Problems and Perspectives. J. Natn. Sci. Coun. Sri Lanka. 17(2) : $165-175$.

11. GUNAWARDENA, N.E. \& HERATH, H.M.W.K.B., t-2-hexenal/n-tridecane; A natural Fumigant of the Defensive Secretion of Coridius janus (Hemiptera; Pentatomidae). J. Natn. Sci. Coun. Sri Lanka. (in press).

12. PESCHKE, K. \& EISNER, T. (1987) Defensive Secretion of the Tenebrionid Beetle Blaps mucronata : Physical and Chemical Determinants of Effectiveness. J. Comp. Physiol. A. 161: 377-388.

13. PETERSON, A. (1964) Entomological Techniques. How to Work with Insects. Edwards Brothers Inc., Michigan.

14. REMOLD, H. (1962) Scent Glands of Land Bugs, their Physiology and Biological Function. Nature. 198: 764-768.

15. STADDON, B.W. (1979) The Scent Glands of Heteroptera. Adv. Insect. Physiol. 14: $351-418$.

16. TSCHINKEL, W.R. (1975) A Comparative Study of the Chemical Defensive System of Tenebrionid Beetles - Defensive Behaviour and Ancillary Features. Ann. Entomol. Soc. 68: 439-445.

17. WATERHOUSE, D.F. \& GILBY, A.R. (1964) The Adult Scent Glands and Scent of Nine Bugs of the Superfamily Coreoidea.J. Ins. Physiology. 10: 977-987. 